\title{
ОСОБЕННОСТИ УПОТРЕБЛЕНИЯ ПРОПИСНОЙ БУКВЫ В УЗУСЕ: НА МАТЕРИАЛАХ СОЦИАЛЬНЫХ СЕТЕЙ И ПЕЧАТНЫХ СМИ
}

\section{FEATURES OF THE CAPITAL LETTER'S USAGE IN THE USUS: ON MATERIALS FROM SOCIAL NETWORKS AND PRINT MEDIA}

Ding Qiang

Summary: The article provides comparative analysis of the use of capital letters in two areas of usus - using examples from social networks and print media. The article describes the widespread deviation from the rules in the language of social media. The factors influencing the violation of orthographic rules are identified. The author compares the extent to which orthographic rules are followed in the practice of traditional and modern writing carriers.

Keywords: Internet-communication, print media, capital letter, orthographic norm, orthographic deviation.

\author{
Дин Цян \\ Аспирант, Московский государственный \\ университет имени М.В. Ломоносова \\ moerooo@yandex.ru
}

Аннотация: В статье проведен сравнительный анализ применения прописной буквы в двух областях узуса - на примерах из социальных сетей и печатных СМИ. Рассказывается о широком отклонении от правил в языке социальных сетей. Выявлены факторы, влияющие на нарушение правил орфографии. Автор сравнивает, в какой степени орфографические правила соблюдаются в практике традиционных и современных носителей письменности.

Ключевые слова: интернет-коммуникация, печатные СМИ, прописная буква, орфографическая норма, орфографическая девиация.

темы, его точности и выразительности, небанальности информации, но и на предмет грамотности; корректор проверяет, в том числе, соблюдение норм орфографии; наконец, члены выпускающей группы или дежурный редактор осуществляют финальный контроль.

Сложившаяся внутриредакционная система контроля текстов в печатных СМИ, существующая в общих чертах и до настоящего времени, в целом доказала свою эффективность.

Однако даже она не исключает наличия ошибок в опубликованных текстах. В июне 2015 года (04.06.2015) «Российская газета опубликовала статью, посвященную рейтингу грамотности популярных российских СМИ (https://rg.ru/2015/06/05/gramotnost.html). В рейтинге участвовали 17 печатных и онлайн-изданий, три новостных агентства, пять телеканалов и семь радиостанций. Было проанализировано 15654 статьи, 216047 предложений, 120 часов эфира и более 200 передач радио и телевидения. В комментарии к итогам рейтинга констатировалось, что «ошибок много». В частности, в отношении печатных СМИ отмечалось: «Троечники среди печатных СМИ, а их большинство, делают по две ошибки на страницу текста...».

В упомянутой статье приводился комментарий главного редактора радио "Эхо Москвы", лингвиста Марины Королевой: «- Вал безграмотности только набирает обороты, - говорит она. - И нет никаких причин для того, 
чтобы он стал меньше. Интернет в последнее десятилетие стал дополнительным производителем, транслятором и "усилителем" речевых ошибок. И у тех, кто пишет, и у тех, кто читает, всё больше сбиваются настройки - орфографические, пунктуационные, стилистические. Пока не очень понятно, что с этим делать: не запрещать же безграмотным писать в Интернете... Помочь, наверное, могли бы программы автокоррекции, типа тех, что есть в Word, например». Не все ученые придерживаются мнения об отрицательном влиянии на грамотность со стороны интернета. Можно привести и противоположное, довольно дискуссионное утверждение: «проникновение компьютерного жаргона в общелитературный язык относится к явлениям демократизации и интеллектуализации языка» [5. C. 41].

На наш взгляд, объяснить неграмотность контента, публикуемого в интернете, можно объяснить двумя основными причинами. Во-первых, отсутствием профессиональной филологической подготовки у пишущих. В отличие от СМИ, в интернете может стать автором текста любой желающий. Во-вторых, в интернете контент практические не подвергается контролю на предмет грамотности.

В частности, В отношении применения прописных букв, существуют лишь частичные ограничения со стороны администраторов платформ, на базе которых осуществляются интернет-коммуникации. Если авторы контента неоправданно интенсивно используют прописную букву, контент может быть признан негодным и заблокирован.

Так, yandex.ru публикует «Требования к рекламным материалам», в которых содержатся такие ограничения: «В текстах рекламных сообщений запрещается использование разрядки (написание слов с пробелами между 6 у к в а м и) и использование заглавных букв, помимо случаев, предусмотренных нормами русского языка. В русском языке заглавные буквы принято использовать В начале предложений, в названиях и именах собственных, а также в аббревиатурах, состоящих из заглавных букв» (https://yandex.ru/legal/text_adv_rules/20092011/).

Отметим, эти ограничения введены лишь для рекламных текстов, весь остальной контент, с точки зрения грамотности, публикуется практически бесконтрольно.

Согласно работам Бобунова М.А. [1. С. 6], Сальникова О.Г. [6. С. 60] и Скоробатько В.В. [7. С. 37], неизбежно, что в средствах массовой информации для привлечения внимания читателей используется определенный способ увеличения частоты употребления прописных букв. Нарушения норм орфографии в текстах, публикуемых в соцсетях, происходят и в исследуемой нами области - в избыточном применении прописной буквы. Однако не- которые исследователи считают, что в широком смысле, не только применительно к орфографии, «норма не может конституироваться без ее нарушения»; то есть, если нет нарушения правил, то правила теряют свой смысл [9]. Хакимова Е.М. утверждает, что восприятие прописных букв не должно ограничиваться исследованием традиционных правил орфографии, а должно распространяться на более широкий мир языковой практики [8. C.167].

Рассмотрим ряд примеров, позволяющих сравнить применение прописной буквы в одной из социальных сетей (VK) и в печатных СМИ.

Одним из наиболее распространенных примеров нарушения правил является употребление прописной в обращении с использованием личного местоимения «вы». Вопреки нормам, позволяющим письменное обращение на «Вы» с прописной буквы только в вежливом обращении к одному лицу, нередко встречаются примеры такого обращения к группе лиц, к определённой целевой аудитории.

Так, известное издательство китайской литературы «Шанс Боку» (https://vk.com/gruppashans) публикует в VK объявление Ассоциации развития синологии (http:// russinology.ru/open_dialogue11), в котором содержится приглашение на мероприятие под названием «Лингвистическая гостиная». При этом вполне очевидно, что обращение делается не к одному лицу, а к некой аудитории. Более того, не только к физическим лицам, но и к организациям. Тем не менее, в этом объявлении местоимение «вы» написано с прописной буквы: «Если Вы - кафедра, вуз, научная школа - расскажите коллегам из других городов и стран о своих направлениях исследований, достигнутых результатах, работах!».

Пример одиозен не только по причине обращения на «Вы» к кафедрам, вузам и школам, заведомо являющимися организациями, а не персонами, но и в силу лингвистической профессиональной направленности авторов данного объявления.

В данном случае имеет место нарушение норм орфографии не неграмотными, а вполне образованными пишущими - как и издательство «Шанс Боку», «перепостившее» упомянутое сообщение в своём аккаунте в VK, так и источник этого текста, Ассоциация развития синологии, по определению являются организациями, сотрудники которых должны быть знакомы с нормами орфографии. Таким образом, данный пример показывает, что типичные ошибки, связанные с нарушением норм написания заглавных букв, допускаются и грамотными пишущими.

В параллель этому примеру можно представить публикацию в печатном издании - «Российской газете», 
посвятившей несколько лет назад проблеме правописания «Вы» отдельную публикацию. В статье напоминается: «Единственная ситуация, которая требует от вас написания местоимения Вы с большой буквы, - это официальное письмо, обращенное к одному конкретному человеку» («Российская газета», статья «Вы или вы?», 25.06.2009 https://rg.ru/2009/06/25/vy.html).

Нередко встречаются в социальных сетях и примеры публикаций, авторы которых пишут прописными все буквы в отдельных словах: «Только СЕГОДНЯ нумерология для новых подписчиков БЕСПЛАТНО...» (из поста в сообществе «Психология отношений», VK, 31.03.2021, https://vk.com/wall-40498005_3367970).

Очевидно, что подобный приём используется пишущими для привлечения внимания подписчиков к продвигаемой услуге и к самому сообществу в соцсети.

Вместе с тем даже небольшое региональное печатное издание, сообщая о редакционной акции (бесплатная раздача газеты уязвимым категориям граждан), которой стремится привлечь внимание читателей, делает это корректно. Те же самые слова, что и в предыдущем примере («бесплатно» и «сегодня»), в этом объявлении написаны строчными буквами: «Редакционная акция «Городские новости, доступные для всех!» пришлась североморцам по душе. Сегодня бесплатно свежий номер получили порядка 20 человек» (газета «Североморские вести», 13 сентября 2019, https://s-vesti.ru/news/ ot-redakcii/2020/34698/27979-severomorka-v-podarok-1/ page,27/).

Стремление «повысить» значение отдельных слов встречается в постах социальных сетей нередко. При этом зачастую этот приём применяется необоснованно; патетическая интонация, создаваемая употреблением прописной буквы, выглядит не вполне уместной: «В этом мире можно искать все, кроме Любви и Смерти» (запись в группе «Философия жизни» VK, 31.03.2021, https:// vk.com/wall-29846359_314718).

В сопоставимом примере из известного печатного СМИ авторы, обращаясь к темам любви и смерти, вполне обходятся без повышения тональности и употребления заглавной буквы: «Идеализация чувств - непременное условие выживания человека, даже если тот склонен воспринимать окружающее как единое целое, где переплелись любовь и смерть» («Независимая газета», статья «Любовь и смерть, рука в руку», 15.02.2008, https://www. ng.ru/antrakt/2008-02-15/17_loveanddeath.html).

Ещё один аналогичный пример показывает склонность пишущих в соцсетях выделять отдельные слова заглавными буквами без учёта правил орфографии, в самом будничном случае, связанном с банальным днем рождения: «Чудесный праздник для дочки и для Мамы в особенности» (комментарий пользователя Евы Хариной к записи певицы Елены Темниковой, VK, 27.03.2021, https://vk.com/wall243556640_489211).

Вместе с тем печатное издание (газета «Московский комсомолец» в одном из регионов) даже в упоминании о высоком призвании женщины-матери вполне обходится без прописных букв: «Быть мамой - великое предназначение женщины» (газета МК Красноярск, 29.11.2017, «Мамин праздник», https://kras.mk.ru/articles/2017/11/29/ mamin-prazdnik.html).

Однако встречается неоправданное написание слова «мама» с прописной буквы и в печатных СМИ: «Разве что сама Мама, когда-то обвенчавшаяся с ним на веки вечные». [Валерия Макарова. Мишенька // Литературно-художественный журнал «Волга», 2015]. https://magazines. gorky.media/volga/2015/11/mishenka.html

Надо признать, что трудно упрекать авторов записей в соцсетях, цитирующих высказывания известных людей, если внутри этих цитат содержится избыточное употребление прописной буквы. Упоминая правила успеха для бедных людей от самого богатого китайца, предпринимателя Ма Юня, более известного как Джек Ма, автор записи в соцсети, естественно, сохраняет орфографию исходного источника. Возможно, цитата взята из книги на английском языке - только этим может быть объяснимо появление прописных в тексте китайского автора, ведь в китайской письменности заглавных букв не существует. Вот эта цитируемая в соцсети заповедь Джека Ма: «Бедные люди терпят неудачи из-за одной общей черты: "Их Вся Жизнь Проходит в Ожидании"» (запись пользователя Ирины Марковой, VK, 12.02.2016, https://vk.com/ wall200287536_1264).

В созвучном примере, из статьи о синдроме отложенного счастья, в известном глянцевом журнале, авторы не употребляют прописной буквы, хотя тоже пишут о вечном ожидании счастья в бездействии: «Жизнь при синдроме отложенной жизни превращается в ожидание желанного события» (журнал ELLE, статья «Счастье не за горами: что такое синдром отложенной жизни», https:// www.elle.ru/otnosheniya/psikho/schaste-ne-za-goramichto-takoe- sindrom-otlozhennoi-zhizni/).

Вместе с тем и в печатных СМИ можно встретить случаи, когда слово «счастье» неоправданно написано с прописной буквы. Например: «Ребенка так ждали, так радовались, нам казалось $\nabla$ вот оно Счастье! [Помогите Сереже! // «Русский репортер», 2014]. В данном примере появление прописной можно объяснить (но не оправдать) рекламным характером публикации. Для рекламы избыточное употребление прописной - характерное явление, независимо от того, где она публикуется, в печатных или электронных текстах. 
А вот пример из печатного журнала, где Счастье - это имя собственное, оно упомянуто здесь в ряду названий населенных пунктов, поэтому вполне оправданно пишется с прописной: «Никак не укладывалось в голове, что в городках и селах с такими добрыми, такими мирными названиями - Хорошее, Роскошное, Приветное, Счастье... - хозяйничает война. [Светлана Беллендир. Уфа - Луганск. Дорога дружбы // Ежемесячный общественнополитический и литературно-художественный журнал «Бельские просторы», 2018].

Слепое следование шаблонам американских СМИ, в которых каждое слово в газетных заголовках традиционно принято писать с прописной буквы, приводит иногда к курьезным случаям словообразования, появлению нелепых лексических единиц. Такое словообразование подчас шокирует грамотных читателей: «Смотрю передачу «Прав!да?» на ОТР. И тут в левом нижнем углу вижу надпись: «Тhe Люди». Что вы хотели мне, зрителю, сказать?» (статья «Комсомольцы, волонтёрцы» в «Литературной газете», №14 (6779) (07-04-2021, https://lgz.ru/ article/14-6779-07-04-2021/).

Оказалось, что русское слово с «пришитым» к нему английским артиклем (и слово, и артикль написаны с прописной), вызвавшее своим появлением на телеэкране недоумение читателя, означало всего-навсего название одного из сетевых видеоканалов: «В 2017 году был создан Ютьюб канал «Тhe Люди»» (запись в блоге steep men, 26.06.2020, https://steepmen.ru/anton-liadov/). Очевидно, создатели этого неуклюжего названия стремились к оригинальности и привлечению внимания пользователей. Однако эффект получился обратный - у просвещённой части аудитории подобный подход к словообразованию может вызвать раздражение и даже культурный шок.

Избыточное употребление прописной в составных названиях организаций широко распространено. Однако иногда составное название организации на её официальном сайте и в печатных СМИ пишется правильно, а в названии соответствующего сообщества в соцсети - уже с нарушением правил: каждое слово с прописной. Так, название детского «Лагеря настоящих героев», расположенного на территории известного парка «Патриот» в Подмосковье, упоминается в соцсети так: «Кстати, в этом году Лагерь Настоящих Героев откроет свой первый юбилейный 5 сезон!» (запись в сообществе «Лагерь Настоящих Героев» в VK, 27 февраля 2021, https://vk.com/ realherocamp).

При этом в публикации печатного СМИ (регионального выпуска газеты «Московский комсомолец») название этого же детского лагеря упомянуто вполне корректно - с прописной буквы написано только первое слово составного названия: «В Кронштадте начался второй сбор молодежи в «Лагере настоящих героев»
(MK Санкт-Петербург, 29.07.2020, https://spb.mk.ru/ social/2020/07/29/v-kronshtadte-nachalsya-vtoroy-sbormolodezhi-v-lagere-nastoyashhikh-geroev.html).

Касаясь темы героизма и её освещения в печатных СМИ, уместно упомянуть о недавней публикации, рассказывающей о подвиге российских медиков, выполнявших свой профессиональный долг в условиях смертельной опасности: «Весь мир уже признал - наши медики настоящие герои» (газета «Комсомольская правда», статья о группе хирургов, продолжавших операцию во время пожара в Благовещенском кардиологическом центре, 02.04.2021 https://www.kp.ru/daily/27260.5/4392094/).

В цитируемой публикации сообщается о подлинных героях, при этом авторы создают необходимую тональность повествования без излишнего пафоса, без избыточного использования заглавной буквы в именах нарицательных. Героизм хирургов раскрывается через точные детали репортажа о событиях в горящем здании: «А в операционных шли две плановые операции. Одна из них - сложная, на открытом сердце - коронарное шунтирование. Приехали пожарные, началась экстренная эвакуация из охваченного огнем здания. Но одна медицинская бригада наотрез отказалась покидать операционную».

В отличие от печатных СМИ, для которых характерно больше сдержанности, авторы социальных сетей склонны к патетике, обеспечиваемой нагнетанием прописных букв. И это проявляется даже в текстах по самой заурядной, бытовой тематике. Например: «Меня зовут Максим Лютый и я сторонник Здорового Образа Жизни с большим стажем» (запись в сообществе «Живые Люди Здоровье, Энергия, Мотивация!», 17 января 2021, https:// vk.com/lyudi_zhivie).

Освещая аналогичную тему (здорового образа жизни), авторы публикации в печатном СМИ (газете «Гудок») вполне обходятся строчными буквами. Выразительным средством для передачи ощущения здоровья, свежести, молодости становится у них метафора - образ яблока: «А символом вчерашней акции стали яблоки, которые, по словам начальника вокзала Сочи Максима Левченко, олицетворяют жизнь, здоровье и энергию» (статья о праздновании Дня здоровья «Полезная среда», газета «Гудок», 07. 04. 2021, https://gudok.ru/content/ infrastructure/1559417/).

Нередки случаи неправильного правописания заглавных букв в такой чувствительной сфере как религиозная тематика. Правила орфографии предписывают употребление прописной буквы в слове «церковь» в строго ограниченных случаях. Во-первых, если она упоминается в высоком смысле, в качестве некоего Божественного учреждения. Во-вторых, если слово «церковь» 
используется вместо полного названия религиозной организации (например, вместо «Русская православная церковь»).

Так, в публикации журнала «Историк», повествующей об издании 6 января 1813 года Манифеста императора Александра I о победном завершении Отечественной войны, сообщается: «Счастливая весть пришла под Рождество. И это был пропагандистски выверенный шаг: ведь в те времена главным средством массовой информации являлась Церковь» (https://xn--h1aagokeh.xn--p1ai/ days/2016/01/06/6-yanvarya-1813-goda-izdan-manifestimperatora-aleksandra-i-o-pobednom-zaversheniiotechestvennoj-vojnyi.html)

Очевидно, в приведённом примере из печатного СМИ слово «церковь» написана с прописной буквы, поскольку оно используется вместо полного названия «Русская православная церковь», и это соответствует нормам орфографии.

Если говорить о написании слова «церковь» в соцсетях, то в сообществах официальных религиозных организаций оно пишется правильно. При употреблении слова «церковь» в значении «храм» нормы орфографии предписывают употребление строчной буквы, что мы и видим в следующем примере: «Многие из таких служителей относятся к своим священническим обязанностям только как к работе в церкви» (запись в сообществе Русская Православная Церковь, VK, 06.04.2021, https:// vk.com/russorthodoxchurch).

При этом все три слова составного названия сообщества (Русская Православная Церковь) написаны с прописной, что противоречит нормам русской орфографии - с заглавной буквы должно быть написано только первое слово. Однако в соответствии Правилами церковного правописания (Приложение 3 к Церковному протоколу, https://azbyka.ru/otechnik/Spravochniki/ tserkovnyj-protokol/13), написание всех слов в названии Русская Православная Церковь с прописной буквы считается правильным. При этом в Правилах церковного правописания содержится отсылка к словарям, которые «составлялись и использовались в Издательском отделе (ныне Совете) Московского Патриархата».

В церковно-религиозных и религиозно-философских текстах с прописной буквы пишутся и названия божественных существ, и местоимения их обозначающие. В следующем примере из печатного издания мы видим подобное употребление прописной (упоминание Пресвятой Богородицы и относящихся к ней местоимений): «Некогда соблазнивший Еву дьявол был посрамлен и побежден в тот момент Женщиной, Которая родит в положенный срок Спасителя мира» (газета «Культура», статья «При светлом празднике весны: 7 апреля
- Благовещение Пресвятой Богородицы», 06.04.2021, https://portal-kultura.ru/articles/symbol-of-faith/332336pri-svetlom-prazdnike-vesny-7-aprelya-blagoveshcheniepresvyatoy-bogoroditsy/).

Идентичный пример можно привести и из публикации в соцсети (также на тему праздника Благовещения): «Архангел Гавриил возвестил Ей, что Она обрела величайшую благодать у Бога - быть Материю Сына Божия» (запись в блоге Натальи Михайловой в VK, 07 апреля 2021, https://vk.com/id302024976)

В обоих примерах употребление прописной буквы обусловлено одними и теми же орфографическими нормами. Сравнение этих двух конкретных примеров не обнаруживает явного превосходства в грамотности печатных СМИ над соцсетями.

Как известно, в особом стилистическом употреблении могут писаться с прописной буквы имена нарицательные в текстах, где этим словам придаётся высокий смысл, например: Родина, Человек, Добро, Учитель и т.п. («Правила русской орфографии и пунктуации», полный академический справочник под редакцией Лопатина, § 203, http://orthographia.ru/orfografia.php?sid=81\#pp81). В социальных сетях нередко наблюдается злоупотребление этим правилом, как в следующем примере. Здесь сравниваются три варианта перевода с немецкого языка одного и того же стихотворения Генриха Гейне. В одном абзаце текста несколько раз употребляются целые группы слов, сплошь написанные прописными: «В самом деле, почему строка «На севере диком стоит одиноко», СлОВНО ЗВУК СТРУНЫ, тотчас пробуждает отзвук в наших душах, а строка «На севере мрачном на дикой скале» - такого отзвука не рождает? Ведь почти все то же самое. Тот же смысл, те же почти слова. Но в ЭТОМ-ТО «ПОЧТИ» и содержится ТАЙНА ПОЭЗИИ» (запись в блоге сообщества в VК «МОСКОВСКОЕ ЛЕРМОНТОВСКОЕ ОБЩЕСТВО», «ТАЙНА ПОЭЗИИ», https://vk.com/wall-79012309_1515).

Следующий пример, взятый из печатного издания, демонстрирует более корректное использование прописной в особом стилистическом употреблении, хотя речь идёт тоже о тайне поэзии. С заглавной буквы здесь написано, помимо «Божьего мира», только одно слово -- «Тайна»: «Лирика природы далеко не проста. За описанным пейзажем кроется представление обо всем Божьем мире. Поэзия Фета может помочь и поэту, и читателю прикоснуться к Тайне» (статья в газете «Культура» «От Золотого к Серебряному: чем символисты обязаны старику Фету», 24.03.2021, https://portal-kultura.ru/ articles/books/332105-ot-zolotogo-k-serebryanomu-chemsimvolisty-obyazany-stariku-fetu/).

Анализируя приведённые пары аналогичных примеров употребления прописной буквы в двух областях 
узуса (в печатных СМИ и в соцсетях VK), можно сделать следующие выводы.

Исследователи отмечают появление тенденции к личностному центризму в современном русском языке [4. С. 456-476]. В большинстве примеров, аналогичных по тематике и лексике, но взятых из социальной сети VK, имеет место избыточное употребление прописной буквы. Однако, как видим из примеров, такие случаи встречаются и в печатных СМИ.

В целом всё же можно утверждать, что избыточное употребление прописной буквы более характерно для текстов в социальных сетях. В соответствии с нашей гипотезой, это может объясняться отсутствием системы проверки публикуемых текстов на предмет соблюдения норм орфографии (за исключением требований администраторов платформ к рекламному контенту) и уровнем филологической подготовки пишущих. И.М. Вознесенская и Т.И. Попова считают, что даже интернет-писатели делятся на тех, кто взыскателен к себе, и тех, кто склонен к либерализации [2. С. 50], но первые не могут разбавить пропорцию вторых.

Существующая в печатных СМИ проверки система текстов на предмет грамотности, безусловно, обеспечивает более высокий уровень качества публикуемых текстов по сравнению с соцсетями.

Вместе с тем, уровень снижения грамотности в обществе сказывается в равной степени на всех областях узуса [3. С. 168]. Об этом свидетельствует и проводившийся несколько лет назад рейтинг грамотности печатных СМИ.

Грамотное письмо и речь всегда были и будут достоянием интеллектуальной элиты общества. Категории и грамотных, и неграмотных пишущих присутствуют в различных областях узуса.

Применить к пишущим в соцсетях какую-то систему контроля на предмет соблюдения правил орфографии вряд ли возможно. Однако некоторые эксперты считают, что «помочь, наверное, могли бы программы автокоррекции». Возможно, в ходе дальнейшего технологического развития платформ для коммуникации в соцсетях могут появиться приложения, которые помогут снизить общий уровень нарушения норм орфографии пользователями.

\section{ЛИТЕРАТУРА}

1. Бобунова М.А. Не вырубишь топором // Русская речь. — 1992.— № 5.—C. 58-60

2. Вознесенская И.М., Попова Т.И. Правила речевого поведения в интернет-общении: нормативный этический аспект // Мир русского слова. 2009 . № 3. C. $47-52$.

3. Загоровская 0.В. Языковая норма в современной русской визуально-письменной речи, функционирующей в интернет-коммуникации: к постановке проблемы // Известия Воронежского государственного педагогического университета. 2017. № 4 (277). С. 168-172.

4. Кормилицына М.А. Усиление личностного начала в русской речи последних лет // Русский язык сегодня. 2. М., 2003. С. 465-476.

5. Нам X.Х. Узус, норма и система в контексте современного русского языка: на материале интернет-коммуникации // Мир русского слова - 2013. - № 3. C. 33-43

6. Сальникова 0.Г. Как рождаются заголовки // Русская речь.— 1983.— № 6.-С. 60-62

7. Скоробатько В.В. Восемь бесед о газетном дизайне.- М.: Союз изд. и распространителей печат. продукции, 2003. - 88 c.

8. Хакимова Е.М. Некодифицированные употребления прописных / строчных букв в текстах массовой коммуникации // Вестник Томского государственного университета. Филология. 2018. № 56. С. 166-186.

9. Ямпольская А., Ямпольский М. Нормальное и нормативное // Отечественные записки. 2014. Т. 2. С. 8-24.

(c) Дин Цян (moerooo@yandex.ru). 